\title{
On the origin of metallic conductivity at the interface of LaAIO3/SrTiO3
}

Chen, Yunzhong; Christensen, Dennis ; Trier, Felix; Pryds, Nini; Smith, Anders; Linderoth, Søren

\section{Published in:}

Applied Surface Science

Link to article, DOI:

10.1016/j.apsusc.2012.01.117

Publication date:

2012

Document Version

Publisher's PDF, also known as Version of record

Link back to DTU Orbit

Citation (APA):

Chen, Y., Christensen, D., Trier, F., Pryds, N., Smith, A., \& Linderoth, S. (2012). On the origin of metallic conductivity at the interface of LaAlO3/SrTiO3. Applied Surface Science, 258(23), 9242-9245.

https://doi.org/10.1016/j.apsusc.2012.01.117

\section{General rights}

Copyright and moral rights for the publications made accessible in the public portal are retained by the authors and/or other copyright owners and it is a condition of accessing publications that users recognise and abide by the legal requirements associated with these rights.

- Users may download and print one copy of any publication from the public portal for the purpose of private study or research.

- You may not further distribute the material or use it for any profit-making activity or commercial gain

- You may freely distribute the URL identifying the publication in the public portal 
Provided for non-commercial research and education use. Not for reproduction, distribution or commercial use.

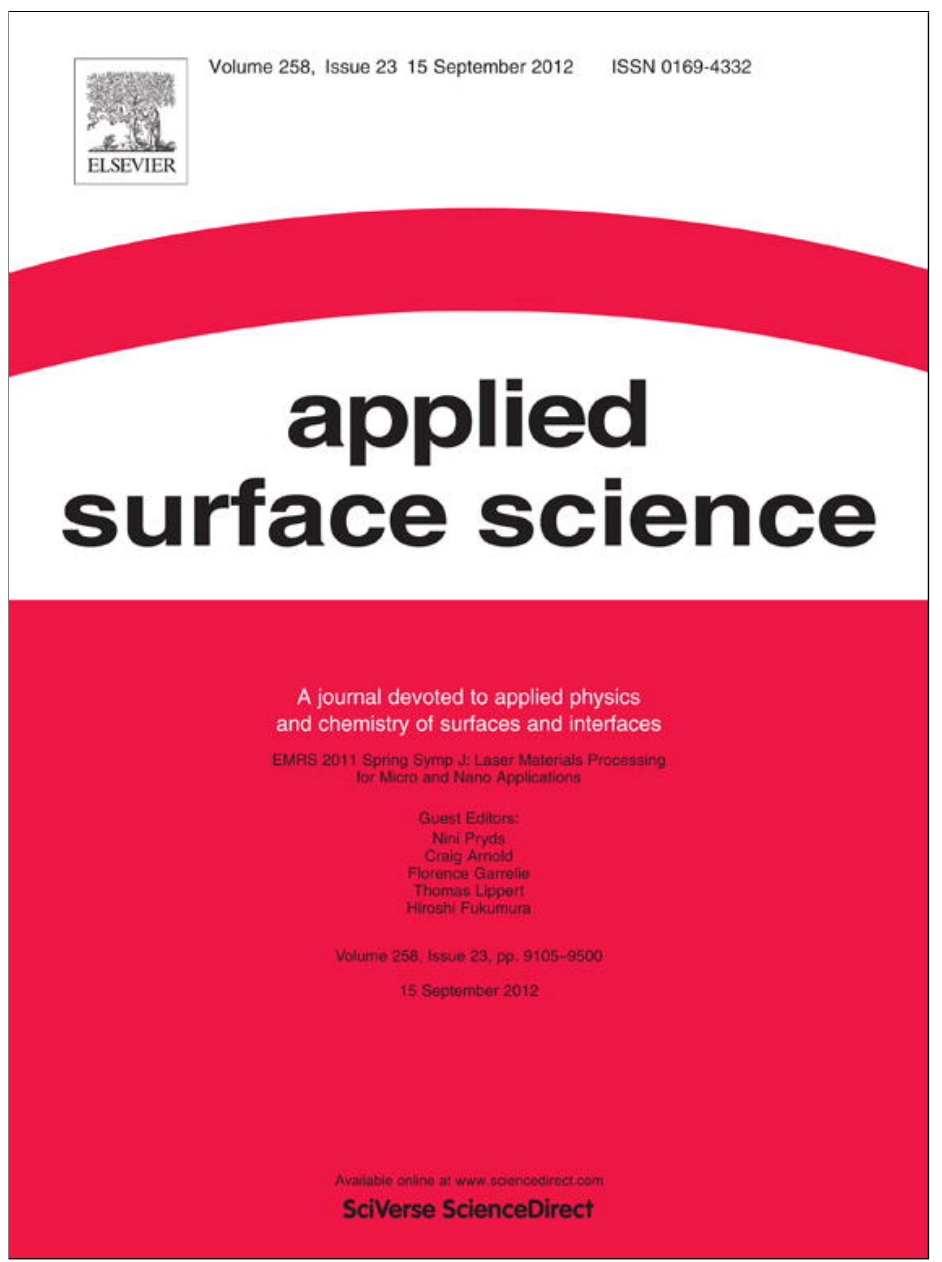

This article appeared in a journal published by Elsevier. The attached copy is furnished to the author for internal non-commercial research and education use, including for instruction at the authors institution and sharing with colleagues.

Other uses, including reproduction and distribution, or selling or licensing copies, or posting to personal, institutional or third party websites are prohibited.

In most cases authors are permitted to post their version of the article (e.g. in Word or Tex form) to their personal website or institutional repository. Authors requiring further information regarding Elsevier's archiving and manuscript policies are encouraged to visit:

http://www.elsevier.com/copyright 


\title{
On the origin of metallic conductivity at the interface of $\mathrm{LaAlO}_{3} / \mathrm{SrTiO}_{3}$
}

\author{
Y.Z. Chen*, D.V. Christensen, F. Trier, N. Pryds, A. Smith, S. Linderoth \\ Department of Energy Conversion and Storage, Technical University of Denmark, Risø Campus, Roskilde 4000, Denmark
}

\section{A R T I C L E I N F O}

\section{Article history:}

Available online 2 February 2012

\section{Keywords:}

Complex oxides

Interface

Metal-insulator transition

$\mathrm{SrTiO}_{3}$ surface

\begin{abstract}
A B S T R A C T
To determine the origin of the quasi-two-dimensional electron gas formed at the interface between the two complex oxides of $\mathrm{LaAlO}_{3}$ (LAO) and $\mathrm{SrTiO}_{3}$ (STO), various amorphous films of $\mathrm{LAO}, \mathrm{La}_{2} \mathrm{O}_{3}, \mathrm{Al}_{2} \mathrm{O}_{3}$, and $\mathrm{La}_{7 / 8} \mathrm{Sr}_{1 / 8} \mathrm{MnO}_{3}$ (LSMO), were deposited on $\mathrm{TiO}_{2}$-terminated (0 01 ) STO substrates by pulsed laser deposition at room temperature. Metallic interfaces are observed when the over-layers are amorphous $\mathrm{LAO}, \mathrm{La}_{2} \mathrm{O}_{3}$, or $\mathrm{Al}_{2} \mathrm{O}_{3}$, while insulating interfaces are observed when the over-layer is LSMO. The interfacial conductivity of these $\mathrm{SrTiO}_{3}$-based hetero-structures shows strong dependence on both film thickness and oxygen pressure during film growth. The possible origin for the occurrence of metallic interfaces in these complex oxide hetero-structures due to redox reactions at the STO substrate surface is discussed. A thermodynamic criterion for designing either metallic or insulating interfaces between complex oxides is proposed.
\end{abstract}

(c) 2012 Elsevier B.V. All rights reserved.

\section{Introduction}

Complex oxides exhibit a wide range of ionic, electronic, and magnetic properties, which have shown extensive applications in multifunctional devices [1]. The recent advances of fabricating oxide materials at atomic level with controlled structure and composition, especially the epitaxial growth of high-quality complex oxide films on unit cell scale [2], provide new challenges and opportunities to explore and design novel materials or devices with tailored properties. A particular example in this area is the observation of metallic conductivity at the interface between the two nominal insulators of $\mathrm{LaAlO}_{3}$ (LAO) and $\mathrm{SrTiO}_{3}$ (STO) [3]. It has been demonstrated that the LAO/STO interface not only exhibits a broad range of interesting physical properties, such as superconductivity [4] and large magnetoresistance [5], but also shows versatile application potentials in oxide electronics, such as electric-field-controlled interfacial conductivity [6,7] and even resistance switching [8]. Nevertheless, the basic question of the mechanism underlying the conductivity at the interface remains unclear [9]. To date, three dominant mechanisms have been proposed to explain the interfacial conductivity [9]. The most prevalent opinion is the electronic reconstruction due to the polar discontinuity at the polar-nonpolar interface [3]. This seems consistent with the observation that the interfacial conductivity only occurs when the LAO thickness equals or exceeds a critical thickness of 4 unit cells $(1.6 \mathrm{~nm})$ [6]. The other two viewpoints rely on the unintentional doping of the STO by La elements from the LAO

\footnotetext{
* Corresponding author. Tel.: +45 4677 5614; fax: +45 46775858.

E-mail address: yunc@dtu.dk (Y.Z. Chen).
}

films [9] or oxygen vacancies formed in STO substrates [10]. Intricately, the latter two mechanisms both exhibit clear experimental evidence $[9,10]$. As a consequence, the situation turns out that the three explanations mentioned above may all play roles in the conductivity at the interface of LAO/STO when the LAO films are deposited at high temperature to form a crystalline structure. However, the mechanism that plays the dominant role in the interfacial conductivity in LAO/STO has not been unambiguously determined. One question that arises is whether the conductivity would also be observed in LAO/STO hetero-structures if the top LAO film is amorphous, where both polar discontinuity and cation intermixing at the interface are expected to be significantly suppressed.

Recently, we grew various amorphous oxide films on STO substrates by pulsed laser deposited (PLD) at room temperature. Remarkably, metallic conductivities were observed at the interface between STO single crystalline substrates and amorphous LAO (aLAO) capping films [11]. Furthermore, the conductivity of these amorphous-crystalline aLAO/STO hetero-structures exhibits critical dependence on both film thickness and oxygen pressure during film deposition, resembling the characteristic features found in the intensively researched crystalline-crystalline samples. We suggested that the conductivity resulted from oxygen vacancies formed on the STO side when the STO surface is exposed to reactive species of the PLD plasma [11]. Here, with the aim to determine the respective roles of the plasma composition on the interfacial conductivity, we further demonstrate that either a $\mathrm{La}_{2} \mathrm{O}_{3}$ or an $\mathrm{Al}_{2} \mathrm{O}_{3}$ plasma can result in a metallic interface conductivity in the formed STO-based hetero-structures. The possible mechanisms for the occurrence of interfacial conductivity are discussed, which are mainly ascribed to the chemical interactions at the hetero-interface 

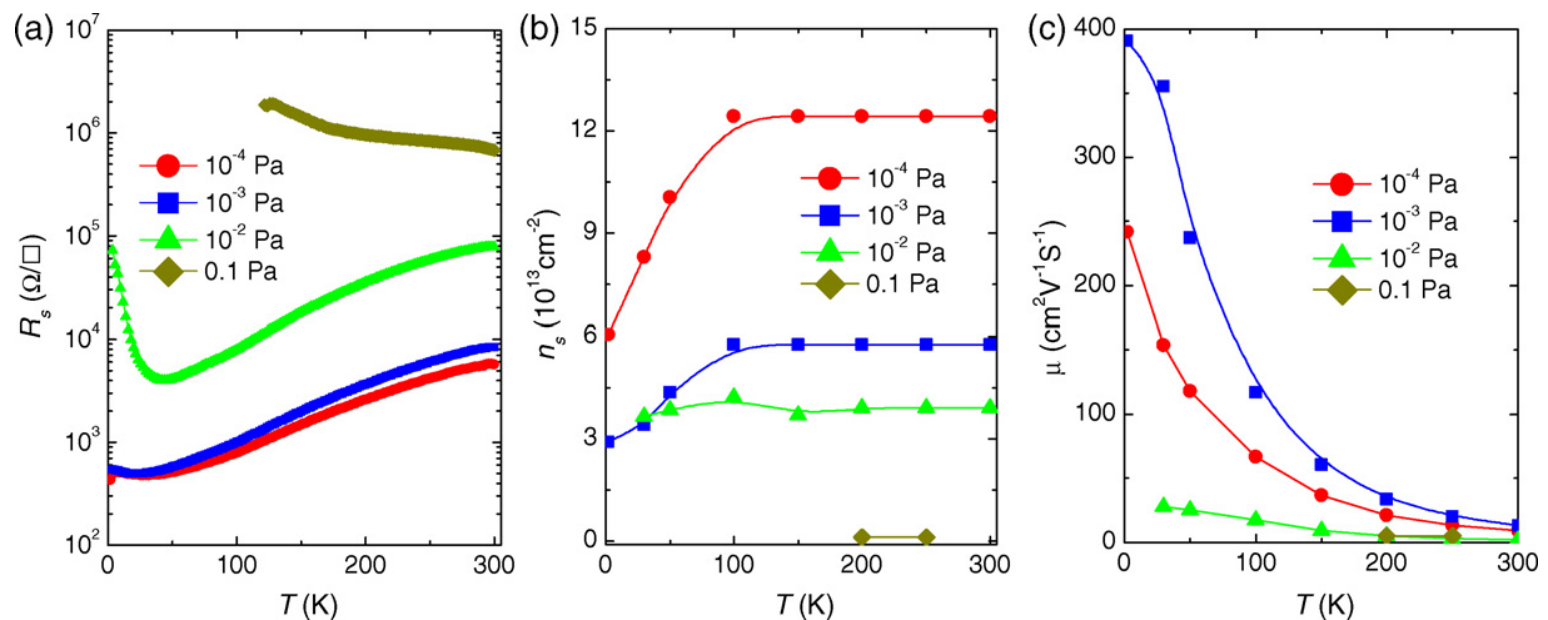

Fig. 1. (a)-(c) The temperature dependent $R_{\mathrm{s}}, n_{\mathrm{s}}$, and $\mu_{\mathrm{s}}$, respectively, for the aLAO/STO samples with amorphous $26.5 \mathrm{~nm}$ LAO films deposited at different $P_{\mathrm{O}_{2}}$.

and can be used to design either metallic or insulating interfaces between complex oxides.

\section{Experimental details}

The LAO, $\mathrm{La}_{2} \mathrm{O}_{3}, \mathrm{Al}_{2} \mathrm{O}_{3}$ and $\mathrm{La}_{7 / 8} \mathrm{Sr}_{1 / 8} \mathrm{MnO}_{3}$ (LSMO) films were grown under different oxygen pressure, $P_{\mathrm{O}_{2}}$, ranging from $1 \times 10^{-4}$ to $100 \mathrm{~Pa}$, by PLD using a $\operatorname{KrF}$ laser $(\lambda=248 \mathrm{~nm})$ with a repetition rate of $1 \mathrm{~Hz}$ and laser fluence of $4 \mathrm{~J} \mathrm{~cm}^{-2}$ at room temperature. The target-to-substrate distance was fixed at $5.0 \mathrm{~cm}$. For depositing LAO films, a commercial LAO single crystal was used as the target. For depositing $\mathrm{La}_{2} \mathrm{O}_{3}, \mathrm{Al}_{2} \mathrm{O}_{3}$ and LSMO films, ceramic targets with nominal composition were used. All films were deposited on singly $\mathrm{TiO}_{2}$-terminated $\left(\begin{array}{lll}0 & 0 & 1\end{array}\right) \mathrm{STO}$ substrates, which were achieved by chemical etching followed by heat treatment [12]. The films were formed in amorphous states. This was confirmed by in situ high pressure reflection high energy electron diffraction (RHEED). The sheet resistance, $R_{\mathrm{S}}$, and carrier density, $n_{\mathrm{s}}$, of the buried interface were measured using a 4-probe Van der Pauw method with ultrasonically wire-bonded aluminum wires as electrodes. The temperature dependent electrical transport and Hall-effect measurements were performed in a Quantum Design physical properties measurement system (PPMS) in the temperature range from $300 \mathrm{~K}$ down to $2 \mathrm{~K}$ with magnetic fields up to $14 \mathrm{~T}$.

\section{Results and discussion}

Fig. 1(a)-(c) shows the temperature dependent sheet resistance, $R_{\mathrm{S}}$, carrier density, $n_{\mathrm{s}}$, and electron mobility, $\mu_{\mathrm{s}}$, respectively, for the aLAO/STO hetero-structures deposited at different $P_{\mathrm{O}_{2}}$. The film thickness, $t$, is about $26.5 \mathrm{~nm}$ for all the samples. As shown in Fig. 1(a), films deposited at $P_{\mathrm{O}_{2}} \approx 1 \times 10^{-4} \mathrm{~Pa}$ and $P_{\mathrm{O}_{2}} \approx 1 \times 10^{-3} \mathrm{~Pa}$, exhibit metallic interfaces from $300 \mathrm{~K}$ down to around $30 \mathrm{~K}$. The electron densities at $T=300 \mathrm{~K}$ obtained from the Hall-effect measurements are $n_{\mathrm{s}}=1.2 \times 10^{14} \mathrm{~cm}^{-2}$ and $n_{\mathrm{s}}=5.8 \times 10^{13} \mathrm{~cm}^{-2}$ for $P_{\mathrm{O}_{2}}$ $\approx 1 \times 10^{-4} \mathrm{~Pa}$ and $P_{\mathrm{O}_{2}} \approx 1 \times 10^{-3} \mathrm{~Pa}$, respectively. For both metallic samples, $n_{\mathrm{S}}$ is constant in the temperature range of $100-300 \mathrm{~K}$. However, a distinct decrease in $n_{\mathrm{s}}$ with decreasing temperature appears at $T<100 \mathrm{~K}$, whereas $\mu_{\mathrm{s}}$ increases gradually with decreasing temperature in the whole range of $2-300 \mathrm{~K}$. Increasing $P_{\mathrm{O}_{2}}$ to $0.01 \mathrm{~Pa}$ results in the presence of a distinct metal-to-insulator transition around $T=40 \mathrm{~K}$ upon cooling at the hetero-interface. Further increasing $P_{\mathrm{O}_{2}}$ to $0.1 \mathrm{~Pa}$ decreases the interface conductivity significantly, where only a semiconducting behavior is observed with $n_{\mathrm{s}}=1.6 \times 10^{12} \mathrm{~cm}^{-2}$ and $\mu_{\mathrm{s}}=4.7 \mathrm{~cm}^{2} \mathrm{~V}^{-1} \mathrm{~s}^{-1}$ around
$300 \mathrm{~K}$. When $P_{\mathrm{O}_{2}}$ is increased to higher than $1 \mathrm{~Pa}$, no measurable interfacial conductivity can be observed anymore. Therefore, the amorphous-crystalline aLAO/STO samples exhibit strong dependence on oxygen pressure of film growth, which is similar to the situation in crystalline-crystalline LAO/STO samples [5]. Meanwhile, it is interesting to note that the carrier density for the amorphous STO-based hetero-structures is of the same order of magnitude as those reported for crystalline LAO/STO heterostructures deposited at high temperature [3-10].

Fig. 2 (a) shows the dependence of the $R_{\mathrm{S}}$ on film thickness at $T=300 \mathrm{~K}$ for the aLAO/STO hetero-structures deposited at different oxygen pressure of $1 \times 10^{-4}, 1 \times 10^{-3}$, and $0.01 \mathrm{~Pa}$. As shown in the figure, the interface is highly insulating below a critical value around $t=1.8 \mathrm{~nm}, t=2.7 \mathrm{~nm}$ and $t=5.4 \mathrm{~nm}$ for $P_{\mathrm{O}_{2}}$ of $1 \times 10^{-4} \mathrm{~Pa}, 1 \times 10^{-3} \mathrm{~Pa}$ and $0.01 \mathrm{~Pa}$, respectively. However, the interface switches to conductive once the film thickness is higher than the critical value. More interestingly, the interface obtained at $P_{\mathrm{O}_{2}}$ of $1 \times 10^{-4} \mathrm{~Pa}$ and $1 \times 10^{-3} \mathrm{~Pa}$ turns from the highly insulating states to metallic states directly, as shown in Fig. 2(b) for $P_{\mathrm{O}_{2}}=1 \times 10^{-4} \mathrm{~Pa}$. These metallic states are quite different from the resistive states observed at the higher $P_{\mathrm{O}_{2}}$ of $0.01 \mathrm{~Pa}$ and $0.1 \mathrm{~Pa}$ as shown in Fig. 1(a), though a resistance abnormality at $T \approx 250 \mathrm{~K}$ is observed in the $t=1.8 \mathrm{~nm}$ sample. In short, the amorphous-crystalline aLAO/STO samples also exhibit a critical thickness effect, which is a prominent feature of the crystalline-crystalline samples [6]. This is rather striking, since the threshold film thickness of $t \approx 1.6 \mathrm{~nm}$ has been regarded as the minimum thickness requirement for the occurrence of charge transfer to alleviate the "polar catastrophe" in crystalline LAO/STO samples [6]. However, the "polar catastrophe" is negligible in the amorphous-crystalline samples investigated here since there is no long-range translational symmetry in the amorphous over-layers. From Fig. 2(a), it is also indicated that the critical thickness for the occurrence of interface conductivity increases with enhanced oxygen background pressure, which is also not compatible with the "polar catastrophe" viewpoint.

As for the origin of the conductivity, the signature of $\mathrm{Ti}^{3+}$ near the interface as determined by in situ X-ray photoelectron spectroscopy (XPS) measurements indicates that the oxygen vacancies on the $\mathrm{SrTiO}_{3}$ side may account for the conductivity in these heterostructures with amorphous capping films [11]. What is the driving force for the accumulation of oxygen vacancies on the STO side? It has been generally argued that the oxygen vacancies are created by the bombardment due to the high energy of the arriving species during PLD process $[10,13,14]$. However, this should be ruled out here, since it is not compatible with the thickness dependence of 

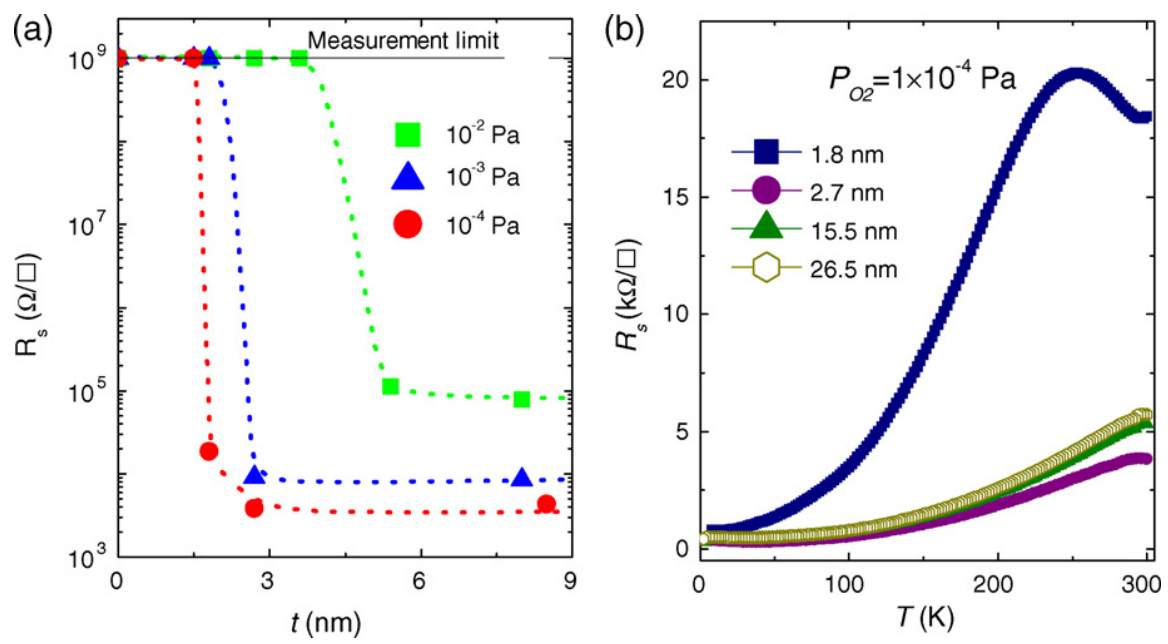

Fig. 2. (a) The film thickness dependent $R_{\mathrm{S}}$ at $300 \mathrm{~K}$ of the aLAO/STO hetero-structures deposited at different oxygen pressure of $1 \times 10^{-4}, 1 \times 10^{-3}$, and 0.01 Pa. (b) The temperature dependence of $R_{\mathrm{S}}$ for aLAO/STO samples with different film thickness deposited at $P_{\mathrm{O}_{2}} \approx 1 \times 10^{-4} \mathrm{~Pa}$.

the conducting behavior as shown in Fig. 2(a) [11]. Furthermore, this is also not consistent with the fact that the deposition of amorphous LSMO (aLSMO) films on STO substrates does not result in any interfacial conductivity as discussed later. Besides the high energy of the plasma species, there are generally a large fraction of neutrals, such as $\mathrm{La}$ and $\mathrm{Al}$, diatomic oxides of the much reactive plume cations, such as $\mathrm{LaO}$, and a small fraction of positive ions and electrons, in the composition of the PLD plasma for $P_{\mathrm{O}_{2}}$ $\leq 0.1 \mathrm{~Pa}$ [14]. We suggest that the oxygen vacancies in STO-based hetero-structures might result from the outward diffusion of oxygen ions from the STO lattice due to the exposure of the STO surface to chemically reactive plasma species during deposition. To determine the respective role of the $\mathrm{Al}$ or La related plasma composition on the outward diffusion of oxygen ions and thus the interface conductivity at the STO surface, we further deposited amorphous $\mathrm{La}_{2} \mathrm{O}_{3}$ $\left(\mathrm{aLa}_{2} \mathrm{O}_{3}\right)$ and amorphous $\mathrm{Al}_{2} \mathrm{O}_{3}\left(\mathrm{aAl}_{2} \mathrm{O}_{3}\right)$ films on $\mathrm{STO}$ substrates at different oxygen pressures.

Fig. 3 shows the $P_{\mathrm{O}_{2}}$ dependence of the sheet conductance at $T=300 \mathrm{~K}$ for the aLAO/STO, $\mathrm{aLa}_{2} \mathrm{O}_{3} / \mathrm{STO}, \mathrm{aAl}_{2} \mathrm{O}_{3} / \mathrm{STO}$ and aLSMO/STO hetero-structures with the film thickness of about $25 \mathrm{~nm}$. Results for the crystalline LAO/STO samples (Refs. $[5,10]$ ) are also given for comparison. As shown in Fig. 3, the interfaces of $\mathrm{aLa}_{2} \mathrm{O}_{3} / \mathrm{STO}$ and $\mathrm{aAl}_{2} \mathrm{O}_{3} / \mathrm{STO}$ are highly insulating at $\mathrm{P}_{\mathrm{O}_{2}}$ of $1 \mathrm{~Pa}$,

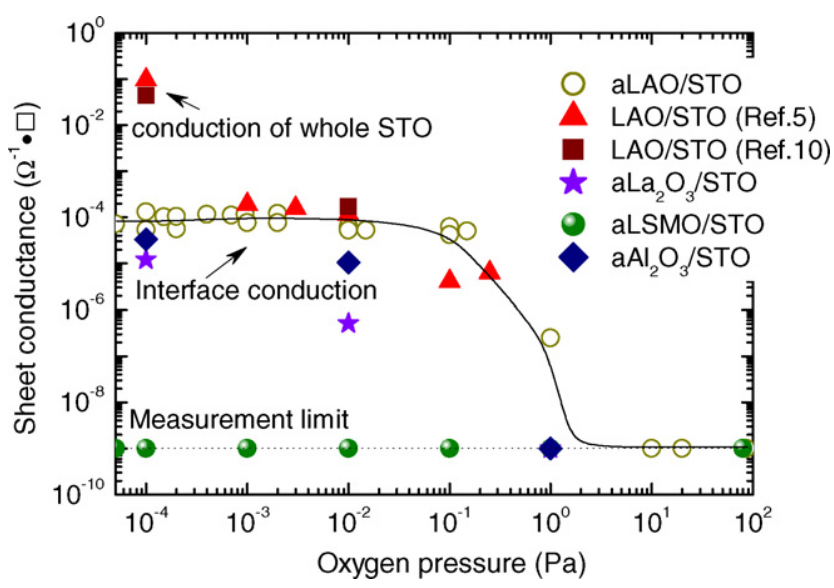

Fig. 3. The dependence of sheet conductance at $T=300 \mathrm{~K}$ on the oxygen pressure of film growth for the aLAO/STO, $\mathrm{aLa}_{2} \mathrm{O}_{3} / \mathrm{STO}, \mathrm{aAl}_{2} \mathrm{O}_{3} / \mathrm{STO}$ and aLSMO/STO heterostructures with film thickness of about $25 \mathrm{~nm}$. Results for the crystalline LAO/STO samples are also shown for comparison. similar to the case of aLAO/STO samples. This may result from the fact that the majority of the reactive species in the PLD plasma have been oxidized due to their significant collisions with the oxygen background gas before reaching the STO surface [14]. Interestingly, conductive interfaces are observed in both $\mathrm{La}_{2} \mathrm{O}_{3} / \mathrm{STO}$ and $\mathrm{Al}_{2} \mathrm{O}_{3} / \mathrm{STO}$ hetero-structures grown at lower oxygen pressures of $1 \times 10^{-4} \mathrm{~Pa}$ and $0.01 \mathrm{~Pa}$. This indicates that both $\mathrm{Al}$ and La related plasma composition could result in oxygen vacancies at the STO surface when depositing at lower oxygen pressure. Therefore, both of them may contribute to the conduction in LAO/STO heterostructures. It has been indicated that the charged species in the plasma composition contribute to the interfacial conductivity [15]. Here, we further suggest that the neutrals of La or Al in LAO plasma should also play a role in the interfacial conductivity.

It should be noted that the oxidization of neutral $\mathrm{La}$ and $\mathrm{Al}$ is generally highly favorable even in the oxygen pressure range of $P_{\mathrm{O}_{2}} \leq 0.1 \mathrm{~Pa}$ due to their high affinity to oxygen. The reason for their presence near the STO surface during PLD film deposition is probably due to the rather high instantaneous growth rate inherent to the PLD process, where a large flux of species (of the order of $10^{20}$ atoms cm $\mathrm{cm}^{-2} \mathrm{~s}^{-1}$ ) incident to the target surface during one laser pulse. In this case, the oxidation of the high flux of cation species during film growth can be kinetically limited by the availability of sufficient oxygen in the chamber, particularly for the low oxygen pressure of $P_{\mathrm{O}_{2}} \leq 0.1 \mathrm{~Pa}$. It is worth noting that when reactive metals, such as $\mathrm{La}$ and $\mathrm{Al}$, contact the STO surface, a redox reaction at the interface occurs by oxidizing the metal overlayer and reducing the oxide substrate through charge transfer from the metal atoms to $\mathrm{Ti}^{4+}$ in STO [16]. For the conventional metal/oxide interfaces, a thermodynamic criterion for the occurrence of metal oxidation on STO surfaces is that the heat of oxide formation per mole of oxygen should be lower than $-250 \mathrm{~kJ} /(\mathrm{mol} \mathrm{O})$ [16]. Surprisingly, most of the conductive interfaces observed in STO-based oxide/oxide hetero-structures prepared by PLD, LAO/STO [3], $\mathrm{LaTiO}_{3} / \mathrm{STO}$ [17], $\mathrm{LaVO}_{3} / \mathrm{STO}$ [18], $\mathrm{CaHfO}_{3} / \mathrm{STO}$ [13], STO/STO [11], Yttria-stabilized zirconia (YSZ)/STO [11], $\mathrm{LaGaO}_{3} / \mathrm{STO}$ [19], and $\mathrm{BiFeO}_{3} / \mathrm{STO}$ [20], consist of cation elements following the above thermodynamic criterion. However, it should be mentioned that the deposition of aLSMO films, whose cation elements also fall in the thermodynamic criterion, do not show any interfacial conductivity, as shown in Fig. 3. This may due to that fact that the oxidation of the reactive metals is also controlled by the space charges at the metal/oxide interface, which is determined by the interface electronic configuration, i.e. the relative Fermi level of the metal and 
that of the oxide before contact [16]. Besides the requirement for the heat of oxide formation $\Delta H_{\mathrm{f}}{ }^{\mathrm{O}}<-250 \mathrm{~kJ} /(\mathrm{mol} \mathrm{O})$, another requirement for the occurrence of room temperature interfacial redox reaction is that the work function of the metals, $\varphi$, is in the range of $\varphi<5.0 \mathrm{eV}$ [16]. Interestingly, for the LAO film growth with conducting interfaces, one of the main neutral species in freelyexpanding plume (at $P_{\mathrm{O}_{2}} \leq 0.1 \mathrm{~Pa}$ ) is $\mathrm{Al}$, which obeys the above criterions. On the other hand, $\mathrm{Mn}$, the main atomic species of the corresponding LSMO plasma, locates on the border region for the occurrence/non-occurrence of redox reactions on the $\mathrm{TiO}_{2}$ surface at room temperature [16]. Therefore, the lack of redox reactions at the interface of our amorphous LSMO/STO samples should explain their insulating interfaces. This argument fits very well with the clearly reduced amount of $\mathrm{Ti}^{3+}$ observed by XPS in the LSMO/STO heterostructure deposited even under $P_{\mathrm{O}_{2}} \approx 1 \times 10^{-4} \mathrm{~Pa}$ [11]. To date, four kinds of STO-based hetero-structures: LAO/STO [11], STO/STO [11], YSZ/STO [11], and $\mathrm{CaHfO}_{3} / \mathrm{STO}$ [13], which consist of ternary $\mathrm{ABO}_{3}$-type complex oxides, have been found to exhibit metallic interfaces that can be realized during room temperature deposition. Interestingly, the B site cation elements in these capping films all follow the above criterions [here, $\Delta H_{\mathrm{f}}{ }^{\mathrm{O}}<-250 \mathrm{~kJ} /(\mathrm{mol}$ O), $3.75 \mathrm{eV}<\varphi<5.0 \mathrm{eV}]$.

Generally, the reduction of the STO substrate shows kinetic limits at room temperature, which is either associated with the redox reaction itself or due to the diffusion limitation of oxygen ions, as demonstrated in the case of metal/oxide interfaces [16]. Therefore, the observed interfacial conductivity in amorphous STO-based oxide hetero-structures deposited at room temperature is suggested to be confined near the interface. When the temperature is elevated, extended out-diffusion of oxygen ions could be activated at rather low oxygen pressure (for STO, this becomes clear above $350^{\circ} \mathrm{C}$ ). This can result in the bulk STO substrate being completely reduced and becoming highly conductive even without any film deposition [21]. The film deposition on STO at high temperature can further enhance the out-diffusion of oxygen ions significantly, such as the case under $P_{\mathrm{O}_{2}} \approx 1 \times 10^{-4} \mathrm{~Pa}$ [22]. On the other hand, high temperatures can facilitate the incorporation of oxygen into the film and the STO substrate at high oxygen pressures [21]. This could remove the oxygen vacancies formed at the interface, and should be the main reason why all the conductive interfaces in STObased hetero-structures, including all LAO/STO samples [3,10], turn insulating after suitable annealing in high oxygen pressure (this process also depends on the annealing time [21]). Therefore, to achieve a conductive interface in complex oxide hetero-structures, it is essential to understand how to freeze the oxygen vacancies near the interface, which is a topic related to the defect chemistry of oxides [21,23].

Finally, besides the charged species and neutral metals, a question remains open on whether the oxides in the PLD plume or the ultimately formed oxide film alone could result in a conductive interface when they contact with the STO surface. This seems possible considering that a space charge layer may also appear when two oxides meet at the interface, which could lead to a dramatic change in the interfacial electrical properties. However, this topic is not considered here.

In summary, metallic interfaces are observed in STO-based hetero-structures when the deposited films are amorphous LAO, $\mathrm{La}_{2} \mathrm{O}_{3}$, or $\mathrm{Al}_{2} \mathrm{O}_{3}$, though the interfaces remain highly insulating when the capping film is LSMO. The interfacial conductivity of the amorphous hetero-structures shows strong dependence on both film thickness and oxygen pressure during film growth. The redox reaction at the interface, by oxidizing deposited films and reducing the STO substrate, probably accounts for most of the metallic interfaces observed in these oxide hetero-structures. Besides electronic interactions, chemical reaction related nonstoichiometry near the interface could be an alternative way to design complex oxide hetero-structures with novel physical properties.

\section{Acknowledgement}

We acknowledge J. Geyti, F. B. Saxild, and N. Bonanos for their valuable help.

\section{References}

[1] Y. Tokura, H.Y. Hwang, Nat. Mater. 7 (2008) 694

[2] G.J.H.M. Rijnders, G. Koster, D.H.A. Blank, H. Rogalla, Appl. Phys. Lett. 70 (1997) 1888.

[3] A. Ohtomo, H.Y. Hwang, Nature 427 (2004) 423.

[4] N. Reyren, S. Thiel, A.D. Caviglia, L. Fitting Kourkoutis, G. Hammerl, C. Richter, C.W. Schneider, T. Kopp, A.-S. Ruetschi, D. Jaccard, M. Gabay, D.A. Muller, J.-M. Triscone, J. Mannhart, Science 317 (2007) 1196.

[5] A. Brinkman, M. Huijben, M. Van Zalk, J. Huijben, U. Zeitler, J.C. Maan, W.G. Van der Wiel, G. Rijnders, D.H.A. Blank, H. Hilgenkamp, Nat. Mater. 6 (2007) 493.

[6] S. Thiel, G. Hammerl, A. Schmehl, C. Schneider, J. Mannhart, Science 313 (2006) 1942.

[7] C. Cen, S. Thiel, J. Mannhart, J. Levy, Science 323 (2009) 1026.

[8] Y.Z. Chen, J.L. Zhao, J.R. Sun, N. Pryds, B.G. Shen, Appl. Phys. Lett. 97 (2010) 123102.

[9] S.A. Chambers, M.H. Engelhard, V. Shutthanandan, Z. Zhu, T.C. Droubay, L. Qiao, P.V. Sushko, T. Feng, H.D. Lee, T. Gustafsson, E. Garfunkel, A.B. Shah, J.M. Zuo, Q.M. Ramasse, Surf. Sci. Rep. 65 (2010) 317.

[10] A. Kalabukhov, R. Gunnarsson, J. Borjesson, E. Olsson, T. Claeson, D. Winkler, Phys. Rev. B 75 (2007) 121404R.

[11] Y.Z. Chen, N. Pryds, J.E. Kleibeuker, G. Koster, J.R. Sun, E. Stamate, B.G. Shen, G. Rijnders, S. Linderoth, Nano Lett. 11 (2011) 3774

[12] Y.Z. Chen, N. Pryds, Thin Solid Films 519 (2011) 6330.

[13] K. Shibuya, T. Ohnishi, M. Lippmaa, M. Oshima, Appl. Phys. Lett. 91 (2007) 232106.

[14] C. Aruta, S. Amoruso, R. Bruzzese, X. Wang, D. Maccariello, F.M. Granozio, U. Scotti di Uccio, Appl. Phys. Lett. 97 (2010) 252105.

[15] Y.Z. Chen, E. Stamate, N. Pryds, J.R. Sun, B.G. Shen, S. Linderoth, Appl. Phys. Lett. 98 (2011) 232105

[16] Q. Fu, T. Wagner, Surf. Sci. Rep. 62 (2007) 431.

[17] A. Ohtomo, D.A. Muller, J.L. Grazul, H.Y. Hwang, Nature 419 (2002) 378.

[18] Y. Hotta, T. Susaki, H.Y. Hwang, Phys. Rev. Lett. 99 (2007) 236805.

[19] P. Perna, D. Maccariello, M. Radovic, U. Scotti di Uccio, I. Pallecchi, M. Codda, D. Marre, C. Cantoni, J. Gazquez, M. Varela, S.J. Pennycook, F.M. Granozio, Appl. Phys. Lett. 97 (2010) 152111

[20] G.L. Yuan, A. Uedono, Appl. Phys. Lett. 94 (2009) 132905.

[21] R. Waser, J. Am. Ceram. Soc. 74 (1991) 1934.

[22] M.L. Scullin, J. Ravichandran, C. Yu, M. Huijben, J. Seidel, A. Majumdar, R. Ramesh, Acta Mater. 58 (2010) 457.

[23] K. Sasaki, J. Maier, J. Appl. Phys. 86 (1999) 5422. 